\section{Homeschooling (Homeschool Education)}

\author{
Rik Carl D'Amato and Carly Gundrum \\ School of Psychology, The Chicago School of \\ Professional Psychology, Chicago, IL, USA
}

The traditional education system typically includes students leaving their home and attending a local school where they attend on a daily basis 5 days per week. However, for a variety of reasons, some families decide not to send their children to public schools and instead decide to provide education within the home setting (Medlin 2011). This may happen for a number of reasons, some of which include the health of the child, for example, severe medical conditions. In addition, at times, if there are behavioral concerns for a child, homeschooling may be a top choice for education. Homeschooling may also be considered if there is not a school available within a reasonable distance to the home, and, instead, computer-related instruction might be utilized paired with tutor or parent instruction. Lastly, various religions believe that homeschooling is the most beneficial for the child and the family unit. Students who receive homeschooling may receive educational services through a tutor, parent, other family member, computer-related instruction, or a combination of services. Depending on the approach and available resources, homeschooling may be an extremely valuable experience and positive choice for students and their families.

\section{References}

Medlin, R. G. (2011). Home schooling and the question of socialization. Peabody Journal of Education, 7(1-2). Retrieved from http://www.tandfonline.com/doi/abs/ 10.1080/0161956X.2000.9681937 